\title{
PERCEPCIONES, IMAGINARIOS Y ACTIVIDADES ECONÓMICAS DE LA MUJER: UN ABORDAJE PSICOSOCIAL DESDE LA PERSPECTIVA DE GÉNERO
}

\author{
Martha Liliana Palomino ${ }^{74}$
}

\begin{abstract}
RESUMEN
Este artículo se fundamenta en los resultados de la investigación del semillero Construyendo Conocimiento con Visión de Equidad, cuyo tema central fue el papel de la mujer y las relaciones de género al interior de la familia. Se intentó dar respuesta a los siguientes interrogantes: ¿Cómo afectan los factores psicosociales en el desarrollo integral de la mujer? ¿Cómo incide el aspecto económico en la manera de pensar de las mujeres?
\end{abstract}

Esta investigación se realizó con 17 madres gestantes y lactantes, entre los 19 y 40 años de edad, integrantes de uno de los Grupos Familia, Infancia y Mujer (FAMI), del Instituto Colombiano de Bienestar Familiar (ICBF), barrio El Porvenir, municipio de Santander de Quilichao. Nueve (9) participaron en el segundo periodo del año 2008 y ocho (8) durante el segundo periodo de 2009. La metodología utilizada como proceso de indagación fue cualitativa a través de reuniones comunitarias, talleres, entrevistas y la observación participante.

Entre los resultados más significativos se encuentra que se logró una descripción de los imaginarios, percepciones y prácticas con relación a las relaciones de género al interior de la familia. El análisis nos muestra cómo el significado y el rol de ser mujer aún se conserva de manera tradicional con algunos cambios en el rol del hombre. Entre los factores psicosociales incidentes en el desarrollo integral de la mujer se identifican el crecimiento personal, las relaciones interpersonales e intrafamiliares y el sentido de vida.

El sentido de vida de las madres del Grupo Familia, Infancia y Mujer(FAMI), está relacionado con su familia, con sus hijos, sus motivaciones personales y el vínculo con Dios. Entre sus sueños y proyectos de vida se destacan el terminar sus estudios de bachillerato, realizar una carrera profesional, tener trabajo para ayudar a su familia y tener una vivienda propia.

Palabras clave: mujer, familia, género, desarrollo, actividades económicas.

\begin{abstract}
ABSTRAC
This article is based on the results of the investigation of the seedbed for Knowledge Building Research in Vision Fair, whose theme was the role of women and gender relations within the family. An attempt to answer the following questions: How do psychosocial factors in the overall development of women? How does the economic aspect in the way of thinking about women?

74 Grupo de Investigación Social GIS, Código Registro Colciencias: código OL0039179. Nombre del Semillero: Construyendo Conocimiento con Visión de Equidad.Línea de Investigación: Mujer, desarrollo y equidad de género. Red de Investigación: Desarrollo comunitario, participación y equidad. UNAD.
\end{abstract}


This research was conducted with 17 pregnant and lactating mothers, aged between 19 and 40 years of age, members of a Family Groups, Children and Women (FAMI), the Colombian Family Welfare Institute (ICBF), El Porvenir district, municipality Santander de Quilichao. Nine (9) participated in the second quarter of 2008 and eight (8) during the second quarter of 2009. The methodology used as a qualitative inquiry process was through community meetings, workshops, interviews and participant observation.

Between the most significant results one thinks that there was achieved a description of the imaginary ones, perceptions and practices of the relations within the family. The analysis shows how the meaning and role of being a woman is still preserved in the traditional way with some changes in the role of man. Among the incidents psychosocial factors in the overall development of women identify personal growth, interpersonal relationships and intra-family and the meaning of life.

The sense of life of the mothers of the Group Family, Infancy and Woman (FAMI), is connected to their family, their children, their personal motivations and the relationship with God. Among his dreams and life projects highlights the graduating high school, a career, has a job to help his family and homeownership.

Key words: women, family, gender, development, economic activities.

\section{INTRODUCCIÓN}

Las investigaciones desarrolladas sobre las mujeres han buscado generar conocimientos sobre sus condiciones de vida, la protección de sus derechos, recuperar sus aportes a la sociedad y a la cultura, además de hacerlas visibles a lo largo de la historia y de la vida cotidiana. De allí que hayan surgido centros académicos y organizaciones estatales y no estatales interesados en realizar estos estudios y desarrollar proyectos en su beneficio no solamente en Colombia sino en los diversos países del mundo.

\section{Las mujeres como objeto de estudio}

Entre las posturas que se distinguen en la investigacion sobre las mujeres, Teresita De Barbieri $^{75}$ (1993), destaca dos muy significativas: una primera, que se centra en generar, acumular y revisar información e hipótesis sobre sus condiciones de vida y de trabajo; la creación y la cultura producida por las mismas mujeres. Una segunda, que privilegia a la sociedad como generadora de la subordinación de las mujeres, la cual fundamenta su estudio en las distintas formas de relaciones entre hombres y mujeres; y por último, las formas de organización social de una sociedad.

Al revisar la literatura vemos que De Barbarie(1993), distingue tres perspectivas y orientaciones

75 Teórica posestructuralista y cinematográfica italiana, nacida en Milán en 1938 pero radicada en Estados Unidos. Es editora desde 1986 de la prestigiosa revista Feminist Studies/Critical Studies, desde donde ha impulsado un feminismo radical con una nueva lectura de la sociedad. Es una abanderada de la Teoría Queer; Teresa de Lauretis fue la primera en emplear la palabra queer para los homosexuales, lo que hace imposible deducir su sexo. 
teóricas. Teorías que han dado origen y expansión al feminismo y al concepto de género como categoría de análisis. Una primera perspectiva es la denominada "Las relaciones sociales del sexo", que privilegia la división social del trabajo como núcleo motor de la desigualdad dada a partir de las diferencias biológicas entre hombres y mujeres, y el cual ha analizado el papel de la mujer en el mercado laboral, la participación sindical y el cambio tecnológico. En esta perspectiva se destaca como principal exponente Danielle Kergoat (Socióloga, investigadora del Grupo de estudios sobre la división social y sexual del trabajo - GEDISST- del CNRS de Francia y autora de diversas publicaciones sobre el tema).

Una segunda referida a quienes estudian la diferenciación desde el género el cual es concebido como un sistema jerarquizado de estatus o prestigio social, el cual permite el aprendizaje de roles que se repiten a lo largo de la vida, con Nancy Chorodow (1978), (Teórica feminista psicoanalítica), como principal exponente. Desde esta perspectiva surgen en la sociedad patrones o estereotipos específicos esperados de personalidad y conducta asignados al hombre y a la mujer; y la sociedad es quien refuerza la desigualdad.

Y la tercera perspectiva, considera los sistemas de género como sistemas de poder resultado de un conflicto social, destacándose Gayle Rubin ${ }^{76}$ como principal exponente, quien hace una crítica feminista a las teorías de Levi - Strauss sobre el parentesco y el psicoanálisis en la vertiente lacaniana desde Barbieri, (1993), ${ }^{77}$ siendo esta última la que ha remitido el análisis de los sistemas de parentesco, la división social del trabajo, la participación en las mujeres en las instancias o sistemas de poder y la subjetividad de los distintos actores del sistema social.

En el origen histórico del feminismo se destaca el patriarcado como principal determinante de la subordinación femenina. Concepto que constituye una estructura primaria de autoridad ejercida por el varón de una familia, desarrollada en las sociedades arcaicas bíblicas y extendidas luego por toda la sociedad. Como concepto y como categoría ha sido ampliamente debatido y superado por los aportes de Rubin (1997), al resultar vacío su contenido de análisis. Desde el punto de vista político contribuyó a la movilización pero no resistió la polémica con los críticos del feminismo, ni permitió dar cuenta de los conflictos inmediatos en la práctica del movimiento, tal como lo menciona Teresa de Barbieri. ${ }^{78}$

\section{El concepto de género}

El concepto de género es múltiple, amplio y polémico por sus diversas implicaciones y perspectivas. Se ha fundamentado en la relación naturaleza - cultura. Ha sido abordado por los diversos movimientos feministas y explicado a partir de la subordinación femenina, la desigualdad social, económica y política de nuestra sociedad.

\footnotetext{
76 Antropóloga cultural y mejor conocida como activista y teórica influyente en políticas de sexo y género. Ha escrito acerca de varios temas que incluyen feminismo, sadomasoquismo, prostitución, pedofilia, pornografía y literatura lesbiana, así como estudios antropológicos sobre sub culturas sexuales.

77 De Barbieri, Teresita. Sobre la categoría de género. Una introducción teórico - metodologica. Instituto de investigaciones Sociales UNAM. Debates en sociología. No. 18 1993. Pág. 7.

78 Sobre la categoría de género. Una introducción teórico - metodologica. Instituto de investigaciones Sociales UNAM. Debates en sociología. No. 18 1993. Pág. 3.
} 
Para iniciar, se realiza un recorrido por sus orígenes gramaticales. Donna J. Haraway citado por Rodríguez $^{79}$ (2005), relaciona el concepto de género con la palabra gender en ingles y genre en Francés. Expresa que tiene su raíz en el verbo latino generare que significa engendrar y el prefijo latino gener, raza o clase. En castellano este hace referencia a clase, especie o tipo a la que pertenecen las cosas. Por ejemplo: un género musical, literario o sencillamente un tipo de tela u objeto. En ingles, género hace alusión a los sexos, mientras que en castellano lo masculino y lo femenino, sólo se comprende en función del genero gramatical, él o ella, Rodríguez, (2005).

Según Donna Haraway, el surgimiento del concepto de género se ubica en 1958, en la universidad de California, en Los Ángeles, donde se desarrolló un proyecto de investigación sobre "La identidad genérica" con el fin de estudiar intersexuales y transexuales. En 1963 Robert Stoller, quien discutió los hallazgos del proyecto antes mencionado hizo una distinción entre el sexo y el género. El sexo lo relaciona con la biología (hormonas, genes, sistema nervioso, morfología, etc.), lo define como algo natural y el género lo relaciona con la cultura, siendo este una construcción social.

Este concepto ayudó a interpretar diferentes fenómenos sociales en diferentes disciplinas en la década de los 70, entre ellas se destacan la Sociología, la Antropología y posteriormente la Psicología. Esto hace que hayan surgido diversas interpretaciones y polémicas al respecto, no sólo con la concepción binaria naturaleza/cultura sino con la relación hombre/mujer.

Según lo anterior, el género no se determina por los aspectos biológicos, se construye social y culturalmente por las diversas interpretaciones y la capacidad de simbolismo del ser humano. Esto ha contribuido a que las diversas culturas hayan establecido diferencias entre hombres y mujeres siendo éstas ultimas excluidas de los poderes políticos y económicos y relegadas sólo al ámbito doméstico, siendo ésta diferencia sexual una implicación de desigualdad social entre hombres y mujeres.

De acuerdo con Estrada (1997), ${ }^{80}$ la conceptualización del género incluye tres momentos en su desarrollo:

Momento 1: el sistema sexo/genero. Este es desarrollado por Rubin, (1975) quien publicó su artículo "El tráfico de mujeres: notas sobre la economía política del sexo". En este momento el foco de análisis del género fue la mujer en el sentido de un sistema cerrado en sí mismo. El sexo fue puesto como la base material para las construcciones sociales. Atribuyéndole así su carácter de existencia como realidad biológica diferenciable: Estrada. El sistema sexo/ género implica una diferencia biológica referida a los órganos genitales, a la reproducción humana y a una construcción social de lo que significa ser hombre y ser mujer, referida a las formas de relacionarse, a la división del trabajo y a la asignación de roles sociales.

\footnotetext{
79 Docente investigadora. Escuela de trabajo social y desarrollo humano. Facultad de Humanidades. Universidad del Valle. Marzo de 2005 .

80 Doctora en Psicóloga Social, magíster en Investigacion y Tecnologías Educativas. Investigadora docente del Programa en Psicología Comunitaria. Facultad de Psicología. Universidad Javeriana.
} 
Para Gayle Rubín citada por Rodríguez (2005), el sistema sexo/género es el sistema de relaciones sociales que transforma la sexualidad biológica en productos de actividad humana. Sistema en el que hombres y mujeres tienen trabajos distintos, donde el uno no puede hacer lo del otro. Entre las actividades de los hombres se destacan el intercambio de mujeres y la opresión de estas. Entre las actividades de las mujeres se destacan la labor doméstica, la satisfacción sexual y la obediencia a los hombres. Esto contribuyó a la opresión y subordinación de las mujeres. Prácticas que pueden ser cambiadas por la lucha política de las mujeres y la transformación de las relaciones de parentesco.

Desde el punto de vista universal, el sistema sexo/género ha sido cuestionado al dejar de lado el problema de la raza y la clase social porque su análisis estaba centrado más en las mujeres blancas occidentales y no en las mujeres del tercer mundo, limitación identificada por las feministas negras norteamericanas. Rodríguez (2005), expresa:

"este cuestionamiento contribuyó a que muchos investigadores trabajaran el concepto de género desde una perspectiva histórica desde la época de la esclavitud, donde las mujeres blancas por las relaciones de parentesco y los lazos de afinidad pasaban a ser propiedad de sus maridos y a constituirse como esposas y como madres, mientras las mujeres negras no lo establecían entre sí con sus compañeros y sus hijos porque eran propiedad de sus amos".

En este caso tanto hombres, mujeres y sus hijos eran subordinados por sus dueños y su dominación no venía de sus esposos sino por pertenecer a una raza o clase. Al respecto Haraway (1991), expone: El concepto de género debe tener en cuenta su interacción con otras categorías estructurales como son la clase y la etnia.

Otro aspecto a discutir es la relación entre género y mujeres, en la que se resalta la participación de las mujeres en las relaciones sociales, políticas y económicas de una sociedad. Esto ha conllevado a que se transforme la familia, la escuela y el trabajo y por ende la sociedad en general. La participación de la mujer muchas veces no ha contribuido a una igualdad de condiciones sino más bien a una sobrecarga de labores y roles contribuyendo aún más a la historia de la marginalidad en los diferentes aspectos de la vida humana.

De acuerdo con Rodríguez (2005), la concepción binaria entre sexo/ género ha sido cuestionada pero ha representado un cambio significativo en colocar a las mujeres en la categoría de cultura, siendo éstas reconocidas como sujetos sociales construidos y autoconstruidas, constituyendo el concepto de género como una herramienta fundamental para el análisis histórico y social. 
Momento 2: la mirada sobre la mujer es también mirada sobre el hombre. El genero como categoría relacional. En este momento se distinguen los aportes de Joan Scout, ${ }^{81}$ Linda Alcoff ${ }^{82}$ y Teresa de Lauretis. ${ }^{83}$ Joan Scout hace su contribución definiendo el género como un elemento constitutivo de las relaciones sociales basadas en las diferencias que distinguen los sexos y el género es una forma primaria de relaciones significantes de poder (Estrada, 1997). Ella explica la naturaleza relacional de la categoría género enfocada en las prácticas y relaciones sociales dadas entre hombre y mujeres histórica y culturalmente.

Linda Alcoff contribuye con la cuestión sobre si existe o no una esencia femenina y en qué consistiría, buscando explicar la naturaleza de cada ser hombre y mujer logrando un valor posicional del género. En este sentido Lauretis basa su definición sobre prácticas y eventos concretos no sólo indagando el lenguaje sino los hábitos y las prácticas cotidianas a fin de comprender la subjetividad históricamente situada tanto en hombres como en mujeres.

Como categoría, el género implica la inclusión de hombres y mujeres en los diversos aspectos de la realidad social. Permite analizar los roles, espacios, atributos y relacionales de poder dados entre estos, además ayuda a visualizar dentro de un sistema de relaciones sociales, lo femenino y lo masculino.

Momento 3: las tecnologías y la reconstrucción del género. Aquí se fundamenta el aporte de Lauretis, surgido en el momento anterior y se desarrolla con el aporte de Judith Butler. ${ }^{84}$ En este momento se destaca el valor político del feminismo desarrollado por Lauretis, ya que no se trata de luchar a favor o en contra de la mujer- ficción del postestructuralismo — sino de reconstruir posiciones concretas socios históricos. ${ }^{85}$ Butler hace un análisis de los discursos históricos inscritos en el cuerpo humano a partir de los aportes de Foucault, a fin de comprender la identidad del sujeto. En este momento se da la proliferación de los géneros y la deconstrucción bipolar de los mismos. Se hace una mirada más transdisciplinar del feminismo y del masculismo.

De los planteamientos anteriores el género se puede referenciar como concepto, como categoría o como relación. Concepto porque explica y da sentido a una realidad; categoría porque clasifica la construcción de sentidos de los hombres y las mujeres; relación porque se da por una posesión o una condición según una cultura, una clase o una raza.

81 Es una historiadora estadounidense con contribuciones en la historia del género y la historia intelectual. Es actualmente Profesora de la Facultad de Ciencias Sociales en el Instituto de Estudios Avanzados en Princeton, Nueva Jersey.

82 Profesora de Filosofía en el Hunter College / CUNY Graduate Center. Trabaja principalmente en la filosofía continental, la epistemología, la teoría feminista, la filosofía latina, y la filosofía de la raza.

83 Teórica postestructuralista y cinematográfica italiana, nacida en Milán en 1938 pero radicada en Estados Unidos. Es editora desde 1986 de la prestigiosa revista Feminist Studies/Critical Studies, desde donde ha impulsado un feminismo radical con una nueva lectura de la sociedad. Es una abanderada de la Teoría Queer; Teresa De Lauretis fue la primera en emplear la palabra queer para los homosexuales, lo que hace imposible deducir su sexo.

84 Filósofa post-estructuralista y profesora del departamento de retórica y literatura comparada de la Universidad de California, Berkeley, que ha realizado importantes aportaciones en el campo del feminismo, la teoría Queer, la filosofía política y la ética.

85 Estrada, Ana Maria. Los estudios de género en Colombia: Entre los límites y las posibilidades. Revista Nómadas. Pág. 39. 
Entre las definiciones de género, Rodríguez (2005), destaca las planteadas por Harding (1983), De Lauretis (1984), y Lamas (1997), quienes resaltan como elementos comunes los siguientes: el concepto de género no debe ser referido exclusivamente a las mujeres; se reconoce que se construye en un sistema de relaciones sociales. Permite transformar la sexualidad biológica en productos de actividad humana, permite otorgarle significado a todas las dimensiones sociales, se relaciona con prácticas, significados, experiencias y relaciones de poder, no sólo entre hombres y mujeres sino entre razas y clases sociales.

Entre la definición más completa Rodríguez (2005), resalta la propuesta por Joan W. Scout, quien define el género como un elemento constitutivo de las relaciones sociales basadas en las diferencias que distinguen los sexos, siendo también una forma primaria de relaciones significantes de poder. Esto nos indica que todo cambio en las relaciones sociales implica un cambio en las representaciones de poder. Este autor resalta cuatro elementos fundamentales: a) Los símbolos culturalmente disponibles que muestran múltiples y contradictorias representaciones; b) Las percepciones normativas que permiten las interpretaciones de los símbolos y quienes afirma el significado de ser hombre y mujer, lo femenino y masculino, manifestadas en doctrinas religiosas, educativas, científicas, legales y políticas; c) La noción política y la referencia a las instituciones y organizaciones sociales, ya que el género no se fundamenta únicamente en las relaciones de parentesco sino en las relaciones laborales y educativa dado por la economía y la política; d) La identidad subjetiva, la cual define la identidad genérica y las relaciones con otros aspectos de la vida histórica, social y cultural especifica.

Desde este punto de vista el género se concibe como algo dinámico, múltiple y diverso que estructura toda forma de relación e interacción social, incluye aspectos objetivos (simbólicos) y subjetivos (construcción de sentido), tiene un carácter individual y colectivo. De esta manera permite comprender las relaciones sociales, las relaciones de poder y las identidades humanas.

\section{Género y perspectivas de desarrollo}

Al hablar de desarrollo se hace referencia a las condiciones que posibilitan una calidad de vida digna, igualdad de oportunidades y sostenibilidad de los procesos naturales, socioculturales, económicos y políticos. De hecho implica una participación protagónica de los diversos actores (hombres y mujeres) de una sociedad.

Tal como lo plantea Gonzales y Niño (1996), los modelos de desarrollo y la cultura acuñada en occidente y en la influencia de los países industrializados, han propiciado relaciones inequitativas no sólo para las mujeres sino para los hombres también. Nos han enseñado que la única forma de relacionarnos entre géneros (hombres y mujeres) se basa en dos premisas el poder y la complementariedad.

Al revisar los hechos históricos de nuestra sociedad se encuentra que estas relaciones han sido reproducidas por la religión, los partidos tradicionales y la sociedad como tal en las que prácticamente se forma familia, pareja, organización y relaciones de amistad, resaltando la imagen y el papel de una autoridad. Autoridad que en la familia siempre ha 
estado bajo el sexo masculino, quien ha tenido poder de decisión y de control sobre ésta, sus bienes y propiedades.

Desde otras miradas, la complementariedad ha buscado resaltar el papel y la posición de la mujer frente al hombre pero basados en la reproducción familiar, en el cuidado y protección de los hijos e hijas y en la expresión del afecto, diferenciándola del hombre, por su debilidad, el silencio y el trabajo doméstico. Ante esta realidad es claro que ni la una ni la otra son las únicas formas viables de relacionamiento, ni de desarrollo. Esto implica revisar las deficiencias, complementos, necesidades y oportunidades a fin de encontrar caminos distintos de la imposición y la manipulación.

En la reproducción social y humana las relaciones entre hombres y mujeres han sido desiguales e inequitativas como causa de los modelos de desarrollo sustentados en la dependencia. Modelos que han posibilitado la imposición y manipulación como la única forma de relacionarnos entre sí, sustentando la obediencia, el silencio y la violencia; valores, actitudes y comportamientos construidos y trasmitidos en todos los espacios de socialización humana tales como la familia, la escuela, la iglesia, el trabajo, la comunidad y por último la misma cultura. De allí que nuestra forma de ser, pensar, actuar y de amar se sustente en la desigualdad y en la inequidad.

Desde esta perspectiva y buscando nuevas maneras de relacionarnos entre géneros se han definido políticas, programas y acciones a favor de procesos incluyentes, mejores estilos de vida, la transformación de problemas sociales, políticos y económicos donde la mujer ha ido posicionando un papel más protagónico distinto al trabajo doméstico aunque aún, se siguen reproduciendo las relaciones inequitativas.

Entre las políticas, programas y acciones se destacan las desarrolladas por la Organización de las Naciones Unidad (ONU), la Organización Internacional del Trabajo (OIT), las organizaciones no gubernamentales (ONG), las organizaciones de mujeres y las conferencias internacionales, buscando generar relaciones de participación, de sostenibilidad y equidad de género en los diferentes países del mundo, principalmente en América Latina.

\section{METODOLOGÍA}

La metodología fue cualitativa abordada desde reuniones comunitarias, talleres de capacitación, la observación participante y la consulta bibliográfica con el propósito de describir y reflexionar sobre las cuestiones de género, las percepciones y prácticas cotidianas de la mujer, su familia y comunidad. La población atendida fueron diecisiete madres entre los 19 y 40 años de edad, gestantes y lactantes del grupo Familia, Mujer e Infancia (FAMI), del Instituto Colombiano de Bienestar Familiar (ICBF), barrio El Porvenir del Municipio Santander de Quilichao. Madres de bajos recursos económicos, con nivel 1 y 2 del Sistema de identificación de potenciales beneficiarios de programas sociales SISBEN en Colombia. 
Para la puesta en marcha del proyecto se definieron seis etapas así:

1. Conformación del equipo de trabajo para el abordaje del proyecto: en esta primera etapa el equipo promotor de la investigación definió el plan de acción, las tareas a desarrollar y estrategias de trabajo. También se definieron las temáticas de abordaje y los talleres a desarrollar.

2. Acercamiento e identificación son el grupo FAMI: se tuvo como propósito el acercamiento preliminar con la líder y las madres integrantes del grupo. Se dio a conocer el proyecto, se identificaron sus expectativas sobre el mismo y se definieron acuerdos de trabajo.

3. Reconocimiento y descripción familiar: se desarrolló a partir de una ficha de reconocimiento aplicada a cada una de las integrantes del grupo, al igual que la elaboración del genograma familiar a fin de conocer su estructura y composición familiar.

4. Tabulación y análisis preliminar de la información: en esta etapa se hizo la tabulación de la ficha de reconocimiento, el genograma familiar y de las observaciones realizadas en las primeras salidas de campo.

5. Indagación y validación de percepciones, imaginarios y sentidos de vida: aquí se seleccionaron como técnicas de indagación la entrevista, los talleres y las reflexiones individuales para la recolección de la información. Este fue un trabajo participativo, expresivo y acorde con las posibilidades y motivaciones del grupo FAMI. Para los registros se tuvo en cuenta la grabadora, la cámara fotográfica, los escritos individuales y los apuntes a través de actas. Para las entrevistas se formuló un cuestionario en relación con las significaciones, funciones y relaciones de acuerdo con el sexo, la igualdad de oportunidades y las actividades económicas ejercidas por cada una de las integrantes; para los talleres se definió un plan temático, una guía planificada y de sistematización final.

6. Análisis e interpretación final: después de recolectada la información y de hacer una revisión bibliográfica se ordenó y se priorizó de acuerdo a los objetivos inicialmente propuestos. Se revisó la sistematización de los procesos abordados y el análisis preliminar buscando comprender la realidad de las mujeres del grupo FAMI, y encontrar nuevos hallazgos y testimonios.

\section{ANÁLISIS DE RESULTADOS}

\section{Descripción de los hogares FAMI: familia, mujer e infancia}

El Hogar Familia, Mujer e Infancia (FAMI) es un programa del Instituto Colombiano de Bienestar familiar (ICBF), el cual se define como el espacio de encuentro y de apoyo a familias con madres gestantes, madres lactantes, con niños y niñas menores de 2 años, que se encuentran en situación de vulnerabilidad psicoafectiva, nutricional, económica y social, prioritariamente de los niveles 1 y 2 del Sistema de identificación de potenciales beneficiarios de programas sociales SISBEN en Colombia.

Estos hogares tienen como propósitos mejorar la función socializadora de la familia y fortalecer la participación del padre, madre y hermanos en el desarrollo de los y las niñas desde su gestación hasta los dos años de edad. De igual manera, cualificar las relaciones familiares, fortalecer el vínculo afectivo padre-madre-hijos - hijas y el fomento de una cultura 
de estilos de vida saludables en la familia. También se promueve la construcción de redes familiares, sociales, comunitarias e institucionales, como gestoras de su propio desarrollo familiar y como estrategias de prevención de la violencia intrafamiliar. Las áreas de énfasis del Programa son: la salud, nutrición, socialización, educación, protección y afecto hacia la niñez, la mujer gestante, lactante la familia y la comunidad.

Atienden un promedio de 12 niños diarios ubicados en los mismos sectores donde habitan las familias (es decir estratos 1 y 2). Estos hogares se establecen en las casas de cada una de las madres líderes ubicados en el mismo sector; con la ayuda y colaboración de otras madres desarrollan actividades educativas y de protección que gracias a su permanente capacitación promueve la lactancia materna para fortalecer la relación madre-hijo, la participación activa del padre en la crianza, la atención de necesidades de supervivencia y seguridad en salud, nutrición, alimentación, desarrollo psicoafectivo y la comunicación intrafamiliar. Estas actividades se dirigen según el grupo poblacional atendido: niños y niñas menores de dos años, la mujer gestante, la madre lactante y toda la familia en general.

Este programa recibe financiación por becas del gobierno nacional a través del Instituto Colombiano de Bienestar Familiar (ICBF), de cuotas de participación de los padres de familia, recursos comunitarios y aportes de personas y entidades públicas, privadas e internacionales. Cada hogar recibe una dotación de material didáctico y alimentación para la población atendida a través de una minuta diaria. La madre líder al final de cada mes el instituto les brinda una remuneración monetaria menor al salario mínimo que le ayuda para cubrir algunos sus gastos personales y familiares.

\section{Descripción familiar de las madres participantes}

Para la descripción familiar se tuvo en cuenta la participación de nueve madres gestantes y lactantes del segundo periodo del año 2008, información recogida a partir de la ficha de reconocimiento y la elaboración del genograma familiar. A continuación se presentan las siguientes características:

A. Sexo y edad de la población: el grupo poblacional atendido fue en su totalidad femenino del cual tres (3) se encontraban entre los 19 y 25 años, cinco (5) entre los 25 y 35 años y una (1) de 40 años de edad respectivamente. Este grupo presentó una edad mínima de 19 años, una edad promedio de 28,44 años de edad y una máxima de 40 años. 


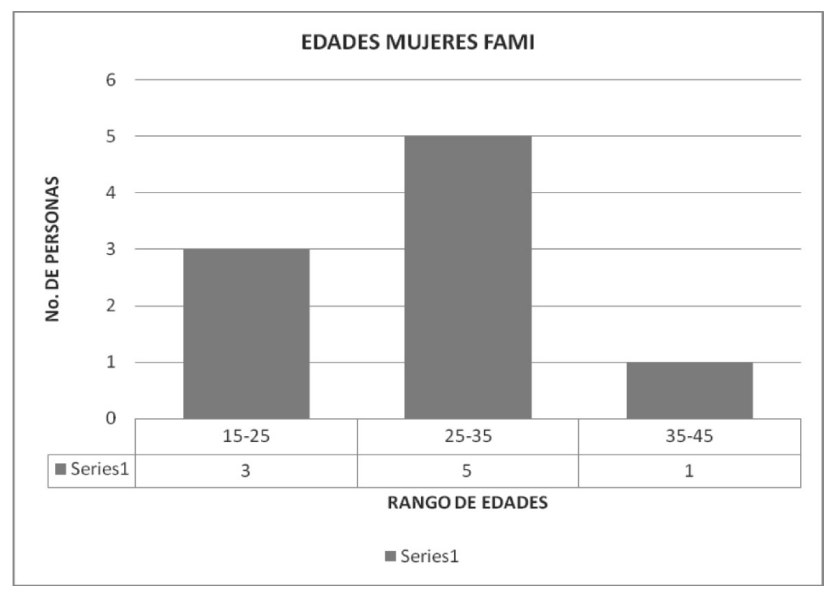

Gráfica 1. Rango de edades de las madres FAMI

Fuente: Ficha de reconocimiento aplicada en esta investigación

B. Nivel educativo de las mujeres FAMI: el nivel educativo de las mujeres se analizó a través del nivel educativo alcanzado primaria, secundaria, técnico, tecnológico y universitario. Los datos indican que el 55.55\% ha terminado solo la primaria, el $33.33 \%$ ha terminado la secundaria y el $11.11 \%$ ha realizado un estudio técnico demostrando un muy bajo nivel de escolaridad.

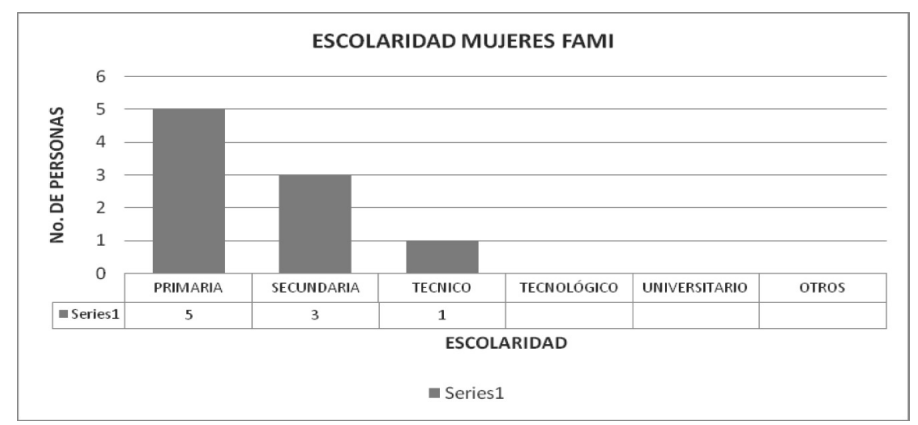

Gráfica 2. Escolaridad de las madres FAMI

Fuente: Ficha de reconocimiento aplicada en esta investigación

C. Estado civil: en su totalidad las mujeres viven en unión libre. Este dato indica que las mujeres tienen establecido un hogar con una pareja estable de relaciones adecuadas y cercanas. Los esposos se encuentran entre los 25 y 40 años de edad, son parejas jóvenes, la mayor población entre los 25 y 35 años, aunque tres (3) de las entrevistadas no respondió este dato. 


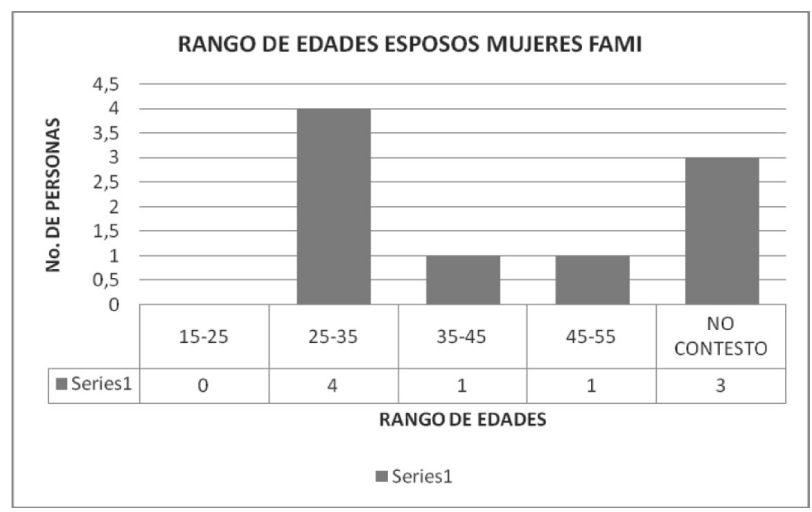

Gráfica 3. Edad de los esposos de las madres FAMI

Fuente: Ficha de reconocimiento aplicada en esta investigación

D.Composición familiar: esta variable indagó la estructura y la composicion familiar de acuerdo con los siguientes indicadores: vive con el esposo y los hijos; vive con el esposo, hijos y la familia del esposo; vive con el esposo, los hijos y su familia. Esto nos indica que de las ocho (8) familias, cuatro (4) son nucleares y cuatro (4) extensas con padres separados.

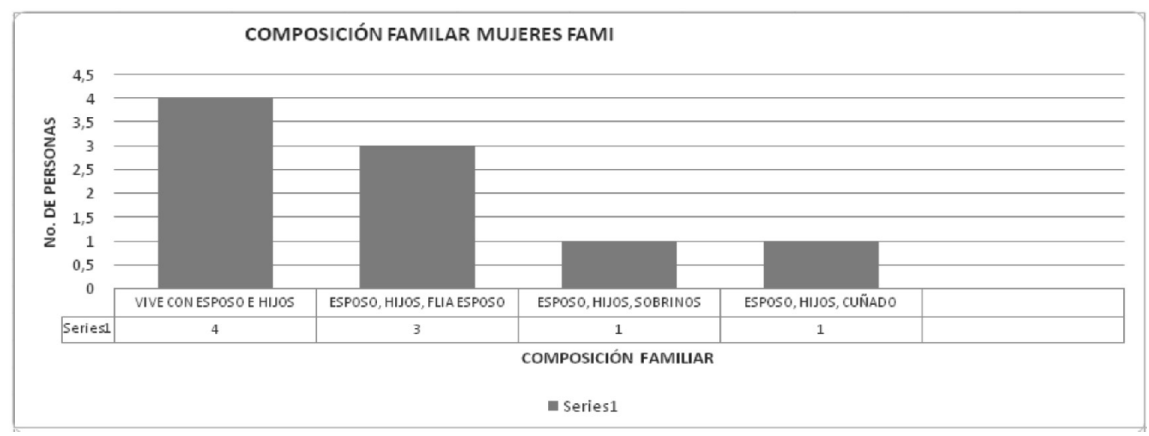

Gráfica 4. Composición familiar

Fuente: Ficha de reconocimiento aplicada en esta investigación

A nivel general estas familias tienen un promedio de 2 hijos que se encuentran entre los $0 \mathrm{y}$ 25 años de edad. Cuatro de ellos están entre los 0 y 15 años y 2 entre los 15 y 25 años como se muestra en la siguiente gráfica. En la ficha de reconocimiento tres de ellas no respondieron este dato. Las relaciones entre los hermanos se evidencian de manera cercana y conflictiva en la mayoría de las familias. El género es diverso y en algunas familias es equitativo. Por lo general, las familias tienen una hija mujer y un hijo hombre. 


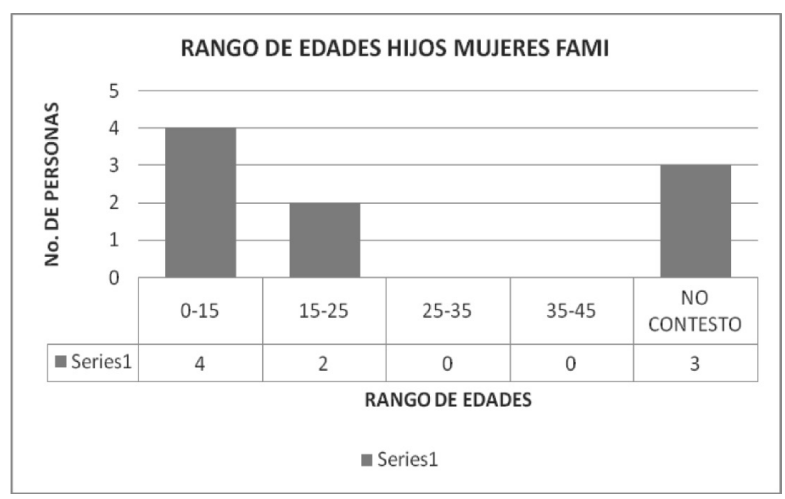

Gráfica 5. Edad de los hijos de las mujeres FAMI

Fuente: Ficha de reconocimiento aplicada en esta investigación

\section{El papel de la mujer en la familia y los factores psicosociales influentes en su desarrollo}

Históricamente el papel de la mujer en la sociedad ha sido determinado a través de aspectos normativos, valorativos, relacionales, simbólicos y subjetivos que la han hecho diferente a los hombres en cuanto a la vida sexual, la procreación y a la actividad laboral pero con la evolución de la sociedad a través del tiempo se han transformado tanto las significaciones como el rol de hombres y mujeres, afectando considerablemente los niveles de vida familiar y social.

En cuanto a las significaciones y el papel de hombres y mujeres se tiene que estas se han constituido socioculturalmente a partir de las diferencias biológicas, las cuales han asignado características, roles y escenarios que diferencian a cada uno de los géneros. Entre las que más resaltan las participantes se encuentran las siguientes:

Tabla 1. Características biológicas de los géneros

\begin{tabular}{|c|l|l|}
\hline CATEGORÍA & \multicolumn{1}{|c|}{ MUJER } & \multicolumn{1}{c|}{ HOMBRE } \\
\hline $\begin{array}{c}\text { CARACTERÍSTICAS } \\
\text { O SIGNIFICACIONES }\end{array}$ & $\begin{array}{l}\text { Delicada, sufrida, tierna, sumisa.Amiga, } \\
\text { consejera, hermana e hija. Maternidad. } \\
\text { Tiene iniciativa para luchar. Con } \\
\text { valores y sentimientos. Con capacidad } \\
\text { para decidir. Amory ternura. }\end{array}$ & $\begin{array}{l}\text { Fuerza, autoridad, poder, seguridad, } \\
\text { protección, proveedor, libertad. }\end{array}$ \\
\hline \multirow{2}{*}{ ROLES } & $\begin{array}{l}\text { Ser mujer, madre y esposa. Ama } \\
\text { de casa, velar por el hogar y } \\
\text { trabajar. Educar a los hijos e hijas. } \\
\text { Acompaña al hombre como esposa. } \\
\text { Actualmente estudia y trabaja. }\end{array}$ & $\begin{array}{l}\text { Proveedor económico y jefe de } \\
\text { hogar. También realizan actividades } \\
\text { etc. Lavan, cocinan, planchan, }\end{array}$ \\
\hline ESCENARIOS & La casa. La escuela. La comunidad. & La calle. El trabajo. \\
\hline
\end{tabular}


La tabla describe que aún se mantienen imaginarios tradicionales de ser mujer y de ser hombre. La importancia de ser mujer va de acuerdo con su rol en el hogar y en la comunidad aunque se evidencian algunos cambios en cuanto a las actividades domésticas, el acceso al sistema educativo, la toma de decisiones y las relaciones intrafamiliares. Es importante resaltar cómo se evidencia la desigualdad de género en el nivel de autonomía, dependencia económica y vulnerabilidad frente a la violencia.

A nivel general las integrantes del grupo se sienten conformes siendo mujeres. Desde la perspectiva de género se destacan las relaciones mujer - madre; mujer - esposa; mujerhermana, mujer - amiga. Sobresale el hecho de que estas mujeres son jóvenes, de baja escolaridad, no trabajan fuera del hogar y pertenecen a un sector pobre. La mayoría tiene esposo, quien ejerce la autoridad en la familia. Esto nos indica que puede existir una subordinación frente a sus cónyuges tal como lo plantea (De Barbieri, 1984; Gonzáles de la Rocha 1986; Gonzáles e Iracheta, 1987; Riquer, 1991; Benería y Roldán, 1992; García y Oliveira, 1994).

Entre los factores psicosociales influyentes en su desarrollo se destacan como relevantes el crecimiento personal, las relaciones interpersonales e intrafamiliares y el sentido de vida. A partir de lo que plantea Barreto (2006), el crecimiento personal se relaciona con auto aceptación, autoestima, autoimagen, autoconfianza y autor respeto. Aspectos importantes de la personalidad de todo ser humano, el cual permite el reconocimiento de sí mismos, el desarrollo de capacidades y el aprovechamiento de las oportunidades de vida. Teniendo como fundamentos las teorías de la personalidad si se tiene un alto crecimiento personal es posible que la mujer pueda desarrollar confianza, mostrar una alta motivación, participar activamente y desempeñar altos cargos.

En las observaciones realizadas a partir de sus interacciones se percibió poca confianza en sí mismas para participar, poco expresivas y de bajo entusiasmo. Esto nos muestra la necesidad de mejorar sus niveles de escolaridad, el nivel de autoestima y la toma de decisiones para facilitar su participación en escenarios que posibiliten su empoderamiento. La participación en otros escenarios de vida como el escolar, el laboral y el comunitario pueden contribuir en la búsqueda de nuevos horizontes y en la autorrealización personal de ellas como mujeres.

Las relaciones interpersonales e intrafamiliares son básicas para el reconocimiento de sí mismas y la convivencia con el otro y con lo otro. Estas relaciones son fundamentales para crear y facilitar ambientes de socialización adecuadas e incorporar comportamientos y características del medio sociocultural en el que se está relacionando. También promueven el proceso de crianza como un mecanismo de formación básica entre padres e hijos. Villegas (2000), expresa: "la crianza humanizada es un proceso en el que la familia hace un aporte significativo; con este tipo de crianza se busca que a partir de las características propias de cada uno de sus integrantes, se logre la formación de un ser social íntegro y con comportamientos concordantes con el medio sociocultural en el que se desarrolla". En este caso tanto las relaciones intrafamiliares como el proceso de crianza pueden o no contribuir a la violencia intrafamiliar o al maltrato infantil. 
Las relaciones familiares y afectivas positivas sustentan la felicidad con el bienestar personal y familiar. A partir de Ibillus (2007), esta felicidad puede estar relacionada con el placer, las personas, el buen trato y las cosas buenas. Sí se carece de las relaciones afectivas y familiares se puede llegar a un estado de infelicidad aunque también depende del estado de ánimo en que se encuentren las personas.

Según López, A. (2003), citado por Ibillus (2007), si una persona amplía su horizonte humano en dirección al infinito, confiere un rango nuevo y superior al sentido de su vida. Esta experiencia excepcional la realizamos cuando respondemos activamente a la palabra que nos trae un mensaje de riqueza sobrehumana y fundamos una relación de encuentro con lo absoluto.

De allí que sea importante ampliar sus horizontes a fin de que puedan identificar y llevar a cabo el pleno desarrollo de su vocación y misión. El sentido se constituye para el hombre y la mujer, en una meta y una tarea siempre renovada, un reto que lo insta a trascender en cada momento los hitos ya alcanzados. (Ibillus 2007, pg.12). El sentido no es estático, varía al entrar en contacto con otras realidades aunque depende del desarrollo personal del ser humano.

El sentido de vida de las madres del grupo FAMI está relacionado con su familia, con sus hijos, sus motivaciones personales y el vínculo con Dios. Su vida se proyecta positivamente de acuerdo con su estado de salud, a las buenas relaciones, al bienestar familiar y a las oportunidades de vida tales como el trabajo y el estudio. Entre sus principales motivaciones de vida también se identifican sus hijos e hijas, sus esposos y sus madres. Esto nos indica que su trayectoria es satisfactoria aunque sus motivaciones no van más allá de sus familias e hijos. Tal vez porque los acontecimientos que han influido notablemente en sus vidas es el nacimiento de sus hijos e hijas así algunas hayan sido separadas o abandonadas por su compañero.

Con respecto al proyecto de vida se indagó teniendo en cuentas tres fases. Corto plazo no superior a 3 meses, mediano plazo no superior a seis meses y largo plazo no superior a un año. A corto y mediano plazo se tienen como indicadores que el $33.33 \%$ desea trabajar, el $11.11 \%$ desea conseguir plata, el $11.11 \%$ desea aprender a coser, el $11.11 \%$ desea estudiar y $33.33 \%$ no responde. Esto nos indica que menos del $50 \%$ de las participantes no tiene definido qué hacer en el último año como se muestra en las gráficas 6 y 7.

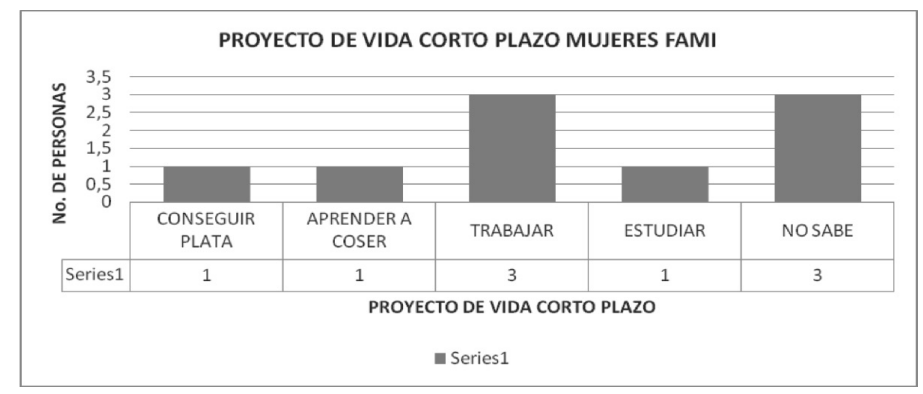

Gráfica 6. Proyecto de vida a corto plazo de las madres FAMI Fuente: Ficha de reconocimiento aplicada en esta investigación 


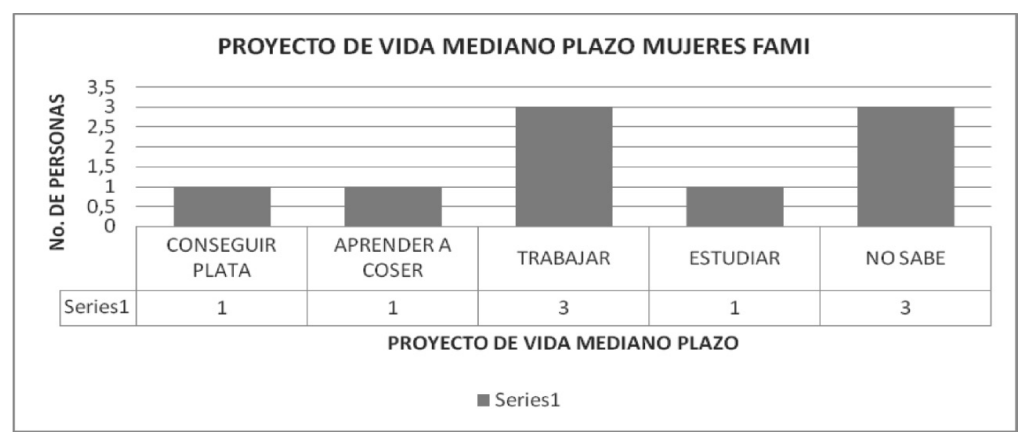

Gráfica 7. Proyecto de vida a mediano plazo de las madres FAMI

Fuente: Ficha de reconocimiento aplicada en esta investigación

Con respecto al proyecto de largo plazo el 33.33\% desea trabajar, el $22.22 \%$ mejorar su calidad de vida, el $11.11 \%$ desea estudiar, el $11.11 \%$ desea conseguir vivienda propia y el $22.22 \%$ aún no sabe.

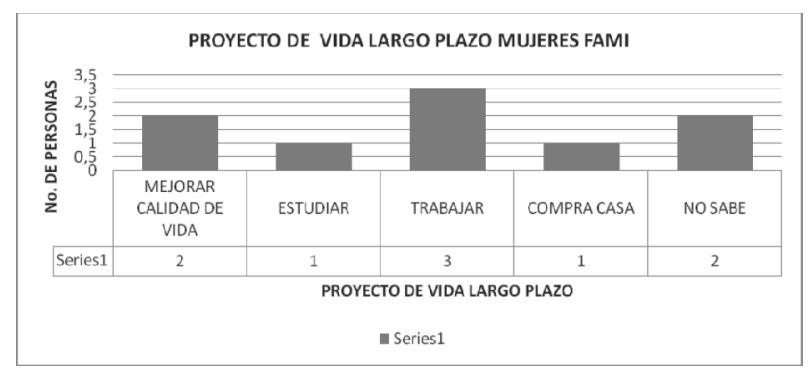

Gráfica 8. Proyecto de vida a largo plazo de las madres FAMI Fuente: Ficha de reconocimiento aplicada en esta investigación

Lo anterior destaca entre sus sueños de vida el terminar sus estudios de bachillerato, realizar una carrera profesional, tener trabajo para ayudar a su familia, tener una vivienda propia y ofrecerles cosas a sus hijos e hijas. Algunas mencionan ser buenas esposas y madres, y estar permanentemente con sus familias. Esto nos indica que la búsqueda de la felicidad puede estar relacionada con las buenas relaciones, la satisfacción de sus necesidades básicas, la realización personal y la búsqueda del dinero como elementos fundamentales de crecimiento, formación, obtencion y supervivencia.

\section{Condiciones económicas de la mujer al interior del grupo FAMI}

La dimensión socio - económica en la familia es fundamental para la satisfacción de las necesidades básicas y la sobrevivencia. También puede manifestar desigualdades de género, distribución inequitativa de tareas y generar cargas de trabajo, al estar bajo el dominio de solo los hombres o solo las mujeres, además puede generar ingresos y recursos 
económicos insuficientes para el mejoramiento de la calidad de vida de las personas. De acuerdo con los estudios de género y algunas intervenciones en políticas públicas se han enfocado principalmente en las mujeres, porque han evidenciado las diferencias y sobre todo desigualdades -o inequidades- que afectan a este grupo en comparación con el de los hombres, es decir, han evidenciado desigualdades de género. SERNAM, Chile (2009).

Al realizar un análisis socioeconómico de las familias integrantes del grupo FAMI objeto de estudio en este investigación se tiene que las fuentes de ingreso que más se destacan son los ingresos del esposo con el $44.44 \%$, el trabajo doméstico con el $22.22 \%$, comerciante con el $11.11 \%$, venta de minutos con el $11.11 \%$ y trabaja en una empresa el $11.11 \%$ como se indica en la gráfica 9. Estos indicadores nos muestran como la mayoría de las mujeres dependen del ingreso del esposo y del trabajo doméstico y las que pueden trabajar desarrollan actividades económicas informales.

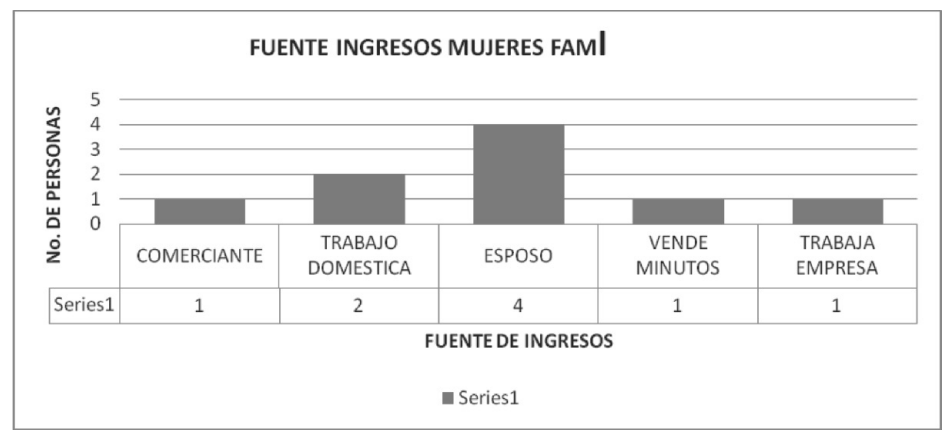

Gráfica 9. Fuente de ingresos de las mujeres FAMI

Fuente: Ficha de reconocimiento aplicada en esta investigación

El nivel de ingresos de estas familias no supera el salario mínimo legal vigente. El 44.44\% tiene al menos 1 salario mínimo, el 22.22\% tiene ingresos inferioares al salario mínimo, el $11.11 \%$ tiene entre 1 y 2 salarios, siendo el esposo quien obtiene dicho ingreso, y el $22.22 \%$ no responde la pregunta.

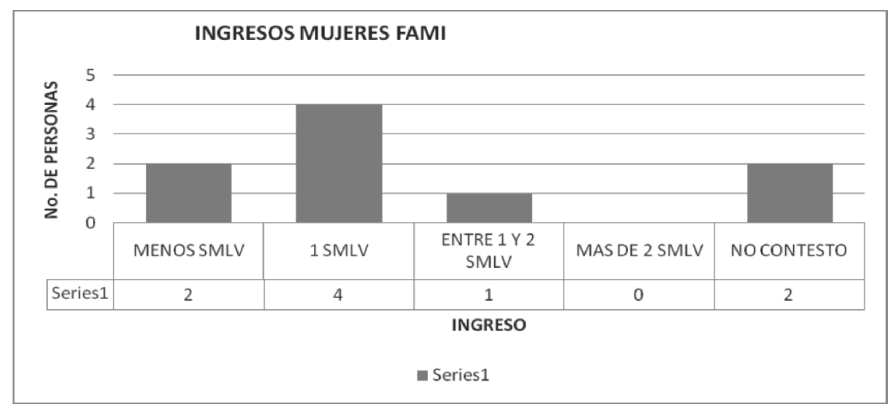

Gráfica 10. Nivel de ingresos de las mujeres FAMI

Fuente: Ficha de reconocimiento aplicada en esta investigación 
Como se mencionó anteriormente entre las actividades productivas no remuneradas realizadas por las integrantes del grupo FAMI se identifican el trabajo doméstico, el liderazgo, la participación que ellas realizan al interior del grupo y la elaboración de manualidades. Entre las remuneradas se identifican las actividades relacionadas con el comercio informal como se muestra en el siguiente cuadro:

Tabla 2. Actividades remuneradas y no remuneradas

\begin{tabular}{|l|l|}
\hline \multicolumn{1}{|c|}{ ACTIVIDADES REMUNERADAS } & \multicolumn{1}{c|}{ ACTIVIDADES NO REMUNERADAS } \\
\hline $\begin{array}{l}\text { Venta de cosméticos por catálogo } \\
\text { (YAMBAL, AVON, ESIKA, etc.) }\end{array}$ & Trabajo doméstico \\
\hline $\begin{array}{l}\text { Venta de minutos (Comcel, Movistar y } \\
\text { TIGO) }\end{array}$ & $\begin{array}{l}\text { Participación y liderazgo al interior del grupo } \\
\text { FAMI. }\end{array}$ \\
\hline $\begin{array}{l}\text { Venta de alimentos en la comunidad } \\
\text { (Fritanga y desayunos) }\end{array}$ & $\begin{array}{l}\text { Elaboración de manualidades (Muñecas de trapo } \\
\text { y dibujos en FOMY) }\end{array}$ \\
\hline Tienda & \\
\hline
\end{tabular}

Ellas realizan estas actividades con el fin de ayudar con los gastos del hogar o satisfacer sus gustos personales. Esta situación se da porque sus esposos no cuentan con un trabajo estable por lo que se sustentan básicamente del rebusque. Algunos días tienen ingreso y otros no. Esto debido a los bajos niveles de escolaridad, al déficit de capacitación técnica y a las pocas oportunidades de empleo en el municipio tanto para hombres como para las mujeres.

Lo anteriormente descrito muestra cómo se evidencian condiciones precarias de trabajo, desprotección laboral, económica y social en la mayoría de estas familias, ampliando cada vez más el ciclo de la pobreza, la discriminación social y la desigualdad de género como causa de la ausencia de oportunidades, la escasa participación en la toma de decisiones, los patrones de segmentación ocupacional en el mercado de trabajo, la falta de acceso a los recursos económicos y a la propiedad.

Es importante mencionar que el bajo poder adquisitivo y la productividad actual de estas familias están asociados con los bajos niveles educativos de los padres y madres de familia, las bajas competencias y oportunidades de empleabilidad y a la pobreza visible en esta comunidad. Además, no se ha reconocido plenamente ni se ha incluido dentro de las políticas nacionales el trabajo doméstico que resulta indispensable para la reproducción social de la familia.

Respecto a la pregunta ¿Cómo incide el aspecto económico en la manera de pensar de las mujeres?, se pueden plantear los siguientes argumentos. Primero, el sistema económico es un mecanismo que la sociedad ha definido para la satisfacción de las necesidades básicas y la generación de riquezas a partir de estrategias y actividades de producción, distribución y consumo de bienes y servicios. En este proceso se identifican las empresas y las personas quienes producen y distribuyen bienes y servicios; y otros principalmente, la familia la principal consumidora de estos. Por lo tanto, el aspecto económico se constituye en un elemento fundamental de desarrollo tanto para la sociedad como para la familia y las personas. 
Segundo, históricamente el aspecto económico siempre ha estado bajo el dominio de los hombres como resultado de la división social del trabajo, viéndose afectadas las mujeres como miembros de los hogares y grupo social desfavorecido. De alguna manera, las mujeres han ejercido el trabajo doméstico y el cuidado de la familia pero no ha sido reconocido laboral ni económicamente. Esto ha hecho que muchas mujeres hayan tenido que intensificar su trabajo para generar algunos ingresos o responder por los gastos del hogar cuando ha sido abandonada por sus parejas, generándoles sobrecarga laboral, y convirtiéndoles en madres cabeza de familia con condiciones precarias de trabajo, relaciones laborales inestables y con escasa protección de seguridad social.

Tercero, a través de políticas públicas se ha avanzado en la participación de la mujer en los escenarios públicos, en el caso de Colombia con la ley de cuotas. Se han desarrollado programas de gobierno, organizaciones no gubernamentales (ONG) y de organizaciones de base que han contribuido con la comprensión de la realidad de la mujer, con la defensa y protección de sus derechos, y el mejoramiento de su calidad de vida pero aún se encuentran condiciones extremas de pobreza, de violencia y desigualdad social que al no ser abordados es difícil superar las condiciones de la mujer actual.

Cuarto, el aspecto económico es fundamental en el desarrollo y en el mejoramiento de la calidad de vida de una sociedad, un pueblo, comunidad o persona pero no es la única condición de desarrollo humano. Como dice Sarmiento (2000), las personas son la finalidad y los agentes de su propio desarrollo. Es una construcción individual y colectiva. Elizalde (2000), expresa: 'lo económico es un medio para alcanzar el desarrollo a escala humana y no el fin". Por lo tanto, es necesario reflexionar en cuanto a los bajos niveles de escolaridad que presentan las mujeres, el bajo reconocimiento y poder de decisión sobre sí misma, la poca autonomía para implementar y desarrollar sus proyectos de vida, la baja organización y cohesión de los grupos donde participan, las dificultades para el manejo de los conflictos interpersonales, intrafamiliares y comunitarios, y la ausencia de liderazgos propios de las mismas mujeres. De allí la importancia de transformar sus actuales condiciones físicas, mentales y psicosociales.

Y quinto, en cuanto a la participación de la mujer en las actividades económicas de la región no existe un estudio relacionado. Se identifican algunas acciones y registros aislados el cual se destacan actividades relacionadas con los oficios varios, el comercio informal, los servicios comunitarios, la docencia, la industria manufacturera, algunas microempresas, la peluquería, el manicure y el mototaxismo. Esto nos indica la necesidad de seguir indagando en cuanto a la participación y el aporte de estas actividades productivas en la percepción y calidad de vida de la mujer Quilichagueña.

\section{CONCLUSIONES}

La construcción de género ha sido un proceso histórico y sociocultural que ha influido en notablemente en los imaginarios, características y roles tanto del ser mujer como del ser hombre. La familia, la escuela y la comunidad han sido los principales agentes de socialización que contribuyen a perpetuar o quizás a transformar las percepciones, los valores (actitudes, 
procesos, cosas, instituciones) y prácticas que sostienen la feminidad y la masculinidad en la actual sociedad.

Las mujeres del grupo FAMI presentan un adecuado estado emocional y de salud mental. No manifiestan frustraciones. Por el contrario, sienten la motivación por mantener una familia, educar adecuadamente a sus hijos, ser buenas madres y esposas. Ellas se sienten felices y dignas de su realidad aunque sienten cierta limitación en cuanto los recursos económicos y a su formación académica. Su felicidad está centrada en el buen estado de salud, en las buenas relaciones familiares y afectuosas. La maternidad se ha convertido para ellas en su sueño de vida, siendo ésta para la sociedad un momento vital para la crianza y la socialización de los hijos e hijas. Pero debido a su bajo nivel académico requieren de formación para la atención, crianza y orientación de sus hijos e hijas.

Entre los sueños de vida de la mujer FAMI se destacan terminar sus estudios de bachillerato, realizar una carrera profesional, tener trabajo para ayudar a su familia, tener una vivienda propia y ofrecerles cosas a sus hijos e hijas. Algunas mencionan la importancia de permanentemente con sus familias a fin de desarrollar procesos adecuados de crianza.

De alguna manera las mujeres madres del grupo FAMI reconocen la violencia y el maltrato como una conducta inadecuada que muchas veces es ejercida por ellas mismas en los procesos de crianza de sus hijos, sin ser consientes muchas veces de ésta. Ellas distinguen más claramente el maltrato físico, psicológico y el abuso sexual como conductas de violencia que niños y niñas sufren constantemente. Conductas conocidas a través de los medios de comunicación. En el contexto comunitario y escolar del sector las madres identifican algún maltrato físico o verbal ejercido por padres y docentes. Describen algunas causas y consecuencias pero muy pocas las estrategias para su abordaje en el sector.

El desarrollo de las actividades económicas de alguna manera tiene influencia en el desarrollo de una sociedad, región, comunidad o familia pero no se constituye en el único elemento de desarrollo humano. Es interesante indagar sí por la inclusión de actividades económicas adecuadas y dignas disminuyen las condiciones de pobreza, violencia, vulnerabilidad y desigualdad de la mujer al interior de la familia y de su comunidad. Sin duda se abren espacios de investigación en el ámbito de la familia, escuela y comunidad, sus significaciones y los efectos en la equidad; la comprensión de la realidad social y económica de las mujeres en el municipio; analizar el impacto de la política nacional de equidad de género y las diversas acciones que se impulsan para el mejoramiento económico de la familia con especial énfasis en la mujer.

\section{REFERENCIAS BIBLIOGRÁFICAS}

APONTE O. D. P; ARIAS H. J. J; CHAVARRO G. J. E; QUIROZ A. J. L. y SOTELO S. N. R. (2007). Diagnóstico de las condiciones de salud y trabajo de las mujeres que laboran en el sector informal de Bogotá. [Ponencia Online] consultado el 10 y 14 de marzo de 2010 en http://search.conduit.com/Results.aspx. 
ASODESI (2003), Relaciones de equidad intrafamiliar. Módulo 3. Escuela de Familia. Versión Preliminar. Lecturas de Apoyo. Bogotá. Colombia.

DE BARBIERI. (1993), Teresita. Sobre la categoría de género. Una introducción teórico metodologica. Instituto de investigaciones Sociales UNAM. Debates en sociología. N.o 18. Pág. 7.

BARRETO. A. (2006), Autoestima y autoimagen. Talleres para el Crecimiento Personal. Paulinas. Bogotá Colombia.

CIBANAL. L. (2008), Genograma Familiar. [Online] consultado el 18 de marzo de 2010 en http://perso.wanadoo.es/aniorte_nic/apunt_terap_famil_8.htm

DE BARBIERI, Teresita. (1993), Sobre la categoría de género: Una introducción teórico metodológica. Debates en sociología. Número 18.

ELIZALDE HEVIA. A. (2000), Desarrollo humano sustentable: sus exigencias éticas, económicas y políticas. Conferencia en el tercer congreso de Bioética de Latinoamérica y el Caribe. Panamá.

ESTRADA, M. Ángela María (1997), Los estudios de género en Colombia: Entre los límites y las posibilidades. Universidad Javeriana. Revista nómadas.

GONZÁLEZ, C. A. NIÑO, G. (1996), Teorías del desarrollo y autogestión. Unisur.

GONZALES, C.A. NIÑO, G. (1996), Teorías del desarrollo con énfasis en autogestión. Santa Fe de Bogotá, D. C., Pg. 155.

RODRÍGUEZ, P. Alba Nubia. (2005), Concepto de género: definición e implicaciones. Documento en proceso. Universidad del Valle.

SARMIENTO, GÓMEZ. A. (2000), Desarrollo humano un encuentro interdisciplinar. Ponencia. Bogotá - Colombia.

SERNAM. Servicio Nacional de la Mujer. (2009), Mejorando la empleabilidad y las condiciones laborales de las trabajadoras jefas de hogar. Gobierno de Chile. [Online] consultado el 10 de marzo de 2010 en http:/www.ascolfa.edu.co/memorias/ MemoriasCladea2009/upac01_submission_579.pdf

TORRES CARRILLO, A. (1997), Enfoques cualitativos y participativos en investigación social. Aprender a investigar en comunidad II. UNAD.

VILLEGAS PEÑA. M. E. (2000), Familia y su relación con la crianza. Boletín del cuerpo de puericultura. Departamento de Pediatría y Puericultura. Facultad de Medicina, Universidad de Antioquia. 